\title{
QUEEN'S
UNIVERSITY
BELFAST
}

\section{Agriculture intensification reduces plant taxonomic and functional diversity across European arable systems}

Carmona, C. P., Guerrero, I., Peco, B., Morales, M. B., Oñate, J. J., Pärt, T., Tscharntke, T., Liira, J., Aavik, T., Emmerson, M., Berendse, F., Ceryngier, P., Bretagnolle, V., Weisser, W. W., \& Bengtsson, J. (2020). Agriculture intensification reduces plant taxonomic and functional diversity across European arable systems. Functional Ecology, 34(7), 1448-1460. https://doi.org/10.1111/1365-2435.13608

Published in:

Functional Ecology

Document Version:

Peer reviewed version

Queen's University Belfast - Research Portal:

Link to publication record in Queen's University Belfast Research Portal

Publisher rights

Copyright 2020 Wiley.

This work is made available online in accordance with the publisher's policies. Please refer to any applicable terms of use of the publisher.

\section{General rights}

Copyright for the publications made accessible via the Queen's University Belfast Research Portal is retained by the author(s) and / or other copyright owners and it is a condition of accessing these publications that users recognise and abide by the legal requirements associated with these rights.

Take down policy

The Research Portal is Queen's institutional repository that provides access to Queen's research output. Every effort has been made to ensure that content in the Research Portal does not infringe any person's rights, or applicable UK laws. If you discover content in the Research Portal that you believe breaches copyright or violates any law, please contact openaccess@qub.ac.uk. 


\section{Agriculture intensification reduces plant taxonomic and functional diversity across European}

arable systems.

Running headline: Intensification reduces plant diversity

Carlos P. Carmona ${ }^{1}$, Irene Guerrero², Begoña Peco ${ }^{3}$, Manuel B. Morales ${ }^{3}$, Juan J. Oñate ${ }^{3}$, Tomas Pärt ${ }^{4}$, Teja Tscharntke ${ }^{5}$, J. Liira ${ }^{1}$, T. Aavik ${ }^{1}$, Mark Emmerson ${ }^{6}$, Frank Berendse ${ }^{7}$, Piotr Ceryngier ${ }^{8}$, Vincent Bretagnolle ${ }^{9,10}$, Wolfgang W. Weisser ${ }^{11}$, Jan Bengtsson ${ }^{12}$

${ }^{1}$ Institute of Ecology and Earth Sciences, University of Tartu, Lai 40, Tartu, 51005, Estonia.

${ }^{2}$ INEA Agricultural Engineering School, Comillas Pontifical University, Valladolid, Spain.

${ }^{3}$ Terrestrial Ecology Group (TEG), Department of Ecology, Research Center on Biodiversity and Global Change, Autónoma University of Madrid. C/ Darwin 2, 28049, Madrid. Spain.

${ }^{4}$ The Swedish University of Agricultural Sciences, Dept of Ecology, Box 7002, SE-745007 Uppsala, Sweden.

${ }^{5}$ Agroecology, Department of Crop Sciences, University of Göttingen, Germany.

${ }^{6}$ Institute for Global Food Security, School of Biological Sciences, 19 Chlorine Gardens, Belfast, BT9 5DL, Northern Ireland, UK.

${ }^{7}$ Department of Environmental Sciences, Wageningen University, PO Box 47, 6700AA Wageningen, The Netherlands.

${ }^{8}$ Institute of Biological Sciences, Cardinal Stefan Wyszyński University, Wóycickiego 1/3, 01-938 Warsaw, Poland.

${ }^{9}$ Centre d'Etudes Biologiques de Chizé, UMR 7372, CNRS and Université La Rochelle, F-79360 Beauvoir-sur-Niort, France.

${ }^{10}$ LTSER « Zone Atelier Plaine \& Val de Sèvre », CNRS, 79360, Beauvoir sur Niort, France

${ }^{11}$ Terrestrial Ecology Research Group, Department of Ecology and Ecosystem Management, School of Life Sciences Weihenstephan, Technische Universität München, Hans-Carl-von-Carlowitz-Platz 2, 85354 Freising, Germany.

${ }^{12}$ Department of Ecology, Swedish University of Agricultural Sciences, Box 7044, SE-700 07, Uppsala, Sweden. 
Corresponding author: Carlos Perez Carmona; Institute of Ecology and Earth Sciences, University of Tartu, Lai 40, Tartu, 51005, Estonia; email: perezcarmonacarlos@gmail.com

\section{Acknowledgements}

We thank the European Science Foundation and the connected national science foundations for funding the presented study through the Eurodiversity AGRIPOPES programme. Financial support was provided by the Estonian Research Council (projects PSG293, MOBJD13 and IUT 20-31), the European Union through the European Regional Development Fund (Centre of Excellence EcolChange), the Spanish MINECO (project CGL2014-53789-R, IJCI-2016-30516), and the Madrid Regional Government (projects REMEDINAL-3 and Remedinal TE). The study has been supported by the TRY initiative on plant traits (http://www.try-db.org). The TRY initiative and database is hosted, developed and maintained by J. Kattge and G. Bönisch (Max Planck Institute for Biogeochemistry for Integrative Biodiversity Research (iDiv) Halle-Jena-Leipzig, Jena, Germany). TRY is currently supported by DIVERSITAS/Future Earth and the German Centre.

\section{Authors' contributions}

CPC, IG, BP, MBM and JO conceived and initiated the study; MBM, JO, IG, TP, TT, JL, TA, ME, FB, PC, VB, WW and JB coordinated data collection from their study regions and/or directly collected data; CPC analysed the data; CPC, IG, BP, MBM and JO and wrote the paper, with inputs from all authors.

\section{Data availability statement}

Data will be deposited in Dryad upon acceptance of the manuscript. 
1 Agricultural intensification reduces plant taxonomic and functional diversity across

2 European arable systems.

3

4

\begin{abstract}
1. Agricultural intensification is one of the main drivers of species loss worldwide, but there is still a lack of information about its effect on functional diversity of arable weed communities.

2. Using a large scale pan European study including 786 fields within 261 farms from eight countries, we analysed differences in the taxonomic and functional diversity of arable weeds assemblages across different levels of agricultural intensification. We estimated weed species frequency in each field, and collected species' traits (vegetative height, specific leaf area and seed mass) from the TRY plant trait database. With this information we estimated taxonomic (species richness), functional composition (community weighted means) and functional diversity (functional richness, evenness, divergence and redundancy). We used indicators of agricultural management intensity at the individual field scale (e.g. yield, inputs of nitrogen fertilizer and herbicides, frequency of mechanical weed control practices) and at the landscape scale surrounding the field (i.e. number of crop types, mean field size and proportion of arable land cover within a radius of $500 \mathrm{~m}$ from the sampling points).

3. The effects of agricultural intensification on species and functional richness at the field scale were stronger than those of intensification at the landscape scale, and we did not observe evidence of interacting effects between the two scales. Overall, assemblages in more intensified areas had fewer species, a higher prevalence of species with ruderal strategies (low stature, high leaf area, light seeds), and lower functional redundancy.

4. Maintaining the diversity of Europe's arable weed communities requires some simple management interventions, for example, reducing the high intensity of field-level agricultural management across Europe, which could be complemented by interventions that increase landscape complexity.
\end{abstract}

Keywords: agricultural intensification; arable plants; functional diversity; landscape; dispersal; species richness; weeds 
Agriculture is the most widespread land use in Europe, occupying roughly $40 \%$ of total land area of the EU-28 (Eurostat, 2018) and harbouring a large part of the continent's biodiversity (Emmerson et al., 2016). Intensification of agricultural management over recent decades has substantially increased crop yields, but the associated environmental costs have been a significant cause for concern for some time (Chamberlain, Fuller, Bunce, Duckworth, \& Shrubb, 2000; Matson, Parton, Power, \& Swift, 1997). Consequently, land use change and agricultural intensification are the principal drivers of species loss worldwide (Green, Cornell, Scharlemann, \& Balmford, 2005; Tilman et al., 2001). Agricultural intensification can also affect which species are present in assemblages depending on their traits, therefore changing functional diversity (Cadotte, Carscadden, \& Mirotchnick, 2011; Flynn et al., 2009). The loss of diversity can in turn affect the structure and functioning of ecosystems, potentially threatening the provision of ecosystem services that sustain our livelihoods (de Bello et al., 2010; Tscharntke, Klein, Kruess, Steffan-Dewenter, \& Thies, 2005). In this context, arable weeds are particularly important for ecosystem services delivered by pest control agents or pollinators (Brooks et al., 2012; Ebeling, Klein, Weisser, \& Tscharntke, 2012; Scherber et al., 2010), providing the resource base in trophic and mutualistic networks in arable systems. As a result, they determine to a high degree the diversity and composition of the associated biota, i.e. insects, birds, and mammals (Butler et al., 2010; Eraud et al., 2015; Evans, Pocock, Brooks, \& Memmott, 2011).

Increases in yields in agricultural production associated with intensification result from changes occurring at two main scales (Emmerson et al., 2016): (i) at the level of the individual field (where practices such as use of high-yielding crop varieties, mechanization, irrigation, and pesticide and fertilizer application directly affect plant communities) (Donald, Sanderson, Burfield, \& van Bommel, 2006; Geiger et al., 2010); and (ii) at the level of the surrounding landscape (processes that lead to smaller species pools and less connectivity, reducing colonization probability) (Sirami et al., 2019; Tscharntke et al., 2012). Different taxonomic groups are likely to respond to different scales of intensification, because species vary in many ways, including mobility, range size, dispersal ability and sensitivity to agricultural disturbance activities (Billeter et al., 2007a). For example, plant diversity can respond more to local management than to landscape complexity (Aavik \& Liira, 2010; Guerrero, Carmona, Morales, Oñate, \& Peco, 2014), while the opposite can occur for mobile 
Despite their adaptations to the particular selection pressures in agricultural fields (Sutherland, 2004), the diversity of arable weeds has been strongly affected by intensification. The effects of intensification on arable weeds are most noticeable at the individual field scale, where a range of management practices focus on reducing their presence and potential impacts on crop yield (Emmerson et al., 2016; Storkey, Meyer, Still, \& Leuschner, 2012). The effectiveness of some of these actions has been called into question, since they are more effective at removing rare plant species than at reducing the densities of competitively dominant and abundant ones (Petit et al., 2016). Here, landscape complexity can play a significant role in maintaining species diversity in arable fields, providing an abundant source of seeds from ruderal habitats and field edges (Gabriel, Thies, \& Tscharntke, 2005). Beyond reducing species richness, management intensity does not affect all arable weed species in the same way. Some species with specific traits or trait combinations are better able to cope with high management intensities (Guerrero et al., 2014). Previous studies have shown lower diversity of functional traits in arable weed assemblages from more intensively managed fields, suggesting that intensification is associated to biotic homogenization (Guerrero et al., 2014; Hevia et al., 2016). This biotic homogenization is further compounded by the loss of functional redundancy along the intensity gradient, with more intensified areas hosting assemblages that are more vulnerable to species losses (Carmona, Guerrero, Morales, Oñate, \& Peco, 2017).

Differences in climatic conditions and the size and composition of species pools can further complicate the study of intensification effects on diversity. Species identity, community composition, trophic complexity and trait diversity might all differ biogeographically and therefore the effects of agricultural management intensity might differ across biogeographical regions. Despite the urgent need for regional- and landscape-scale (large scale) studies that encompass a larger variety of conditions, most of our understanding about the effects of agricultural management intensity on plant diversity comes from studies performed at field scales (local scales). The few studies analysing the effects of land use change at continental or global scales come from meta-analyses that do not focus exclusively on agricultural management intensity, rather they provide insights from a synthesis of studies with a variety of experimental designs (Laliberté et al., 2010; Martin et al., 2019). In this sense, coordinated efforts across different countries with commom sampling methods are much needed, providing important details of the effects of agricultural intensification on 
In this paper, we examine the effects of agricultural intensification, at the local field and landscape level (in a radius of $500 \mathrm{~m}$ ), on the diversity of arable weeds assemblages in fields

100 of cereal-dominated agroecosystems. We analyse a large-scale dataset originally collected using standardized methods (see Emmerson et al., 2016 for a detailed description of the project), and including nine study areas from eight European countries providing strong gradients in agricultural intensity and environment both within- and between-regions. Within these regions we selected fields that differ in the values of agricultural management variables that are commonly used as proxies for agricultural intensification. This space-by-time substitution enabled a characterisation of differences in the impacts of intensification on local diversity between biogeographical regions. In the present study, we aim to (1) identify the relevant scale (individual field or landscape scale) at which agricultural intensification is most strongly associated with local arable weeds diversity; (2) evaluate whether taxonomic and functional diversity respond in similar ways to intensification; (3) investigate how intensification promotes certain functional trait values, leading to changes in the functional diversity and composition of assemblages; and (4) characterize the type of arable weeds communities favoured by current intensification trends.

\section{Material and Methods}

\section{Study areas, farms and fields}

117 Fieldwork was performed in cereal farms in nine study areas (Sweden, Estonia, Poland,

118 eastern and western Germany, the Netherlands, Ireland, France and Spain). In each study

119 area, 30 farms separated by at least one $\mathrm{km}$ were selected, and considered to be representative

120 of a gradient of regional agricultural intensification. Given the diversity of agricultural

121 management practices and the scale of management units in the different countries involved in the study, individual farms were considered the ecological unit under study, and for the purposes of the study each was recognised as a set of one or more fields, separated by a

124 distance of not more than $1 \mathrm{~km}$, which were cultivated by the same farmer (owned or leased),

125 and occupying an area not exceeding $1 \mathrm{~km}^{2}$. These farms were situated in regions between 30

$126 \times 30$ and $50 \times 50 \mathrm{~km}^{2}$ in area, in order to limit within-region variation in the size of species

127 pools and $\beta$-diversity, and to avoid an excessive heterogeneity of landscapes and soil types within each study area. Farms were selected so that the range of cereal productivity in the sample was as large as possible, based on information obtained from the farmers on cereal 
130 yields in the 3 years preceding the study, and with a representative and even distribution across the gradient of productivity in each area. Only cereal crops were sampled on each farm (mainly winter wheat: $80 \%$ of the fields; if wheat was not available on the farm, winter barely was used). Sampled fields were never smaller than 1 ha in size nor irrigated. Sampling took

134 place from June to July 2007, and was synchronized using the phenological stages of winter 135 wheat in each study area (i.e. always during the flowering to milk rippening period within each study area). To further avoid phenological effects, the sequence of farm sampling was randomized over the yield gradient within each study area.

138 For each farm, five sampling points distributed over a maximum of five arable fields were selected for plant sampling. When there were fewer than five fields available, the points were stratified in proportion to size of sampled fields. Sampling points were laid parallel to grassy (never woody) field borders and at $10 \mathrm{~m}$ distances from the border towards the field centre. Weeds were sampled in three $2 \times 2 \mathrm{~m}^{2}$ quadrats per sampling point, placed parallel to the

143 field edge and separated five meters from each other.

Vegetation sampling and agricultural management information

146 We identified the weed species (i.e. all vascular plant species except the crops) present in each sampling quadrat. Then, we pooled the three quadrats within each sampling point, obtaining the frequency of presence of each species in each sampling point. A four-point scale of local-abundance was used ranking sampling locations from 0 (absent) to 3 (present in the three quadrats). Following Guerrero et al. (2014), all subsequent analyses were performed at the sampling point level (since we consider the sampling point as representative of the local community of arable weeds, for brevity we will refer to them as 'assemblages' from now on).

We measured six indicators of agricultural management intensity both at the individual field and at the surrounding landscape scales (Table 1). The indicators of agricultural management intensity associated with the individual field scale were assessed by means of questionnaires, undertaken in person with the farmers responsible for managing the sampled

158 fields, and included measures of yield and inputs of nitrogen fertilizer and herbicides. We 159 used digital maps created from remotely sensed images from each study area to estimate the 160 indicators of agricultural management intensity associated with the landscape scale. These landscape scale measures included the size of the focal field and two measures of landscape 
structure that were quantified within a radius of $500 \mathrm{~m}$ around each sampling point, these were: mean arable field size and the proportion of arable land cover.

Given the multidimensional nature of agricultural intensification, which encompasses many correlated variables, dimensionality reduction is a common way to estimate it (Carmona et al., 2017; Flohre et al., 2011). Accordingly, following Guerrero et al. (2014), we performed a principal component analysis (PCA) on these indicators of agricultural management intensity. We retained two othogonal axes that explained $62 \%$ of the total variance (Table 1; Fig. S1). The first axis (PC1) was related to management practices at the individual field level (contributed by yield, and the number of herbicide and nitrogen fertilizer applications). The second axis (PC2) was related to the structure of the surrounding landscape (and was defined by sampled field size, mean arable field size, and percentage cover of arable crops). We used these axes to produce estimations of agricultural intensity at the local field and landscape level, respectively (Table S1).

\section{Functional trait information and diversity estimation}

We collected functional traits for the species found in the vegetation surveys from the TRY database (Kattge et al., 2020; Appendix S1). We chose three traits that are related to plant strategy for resource capture and allocation: specific leaf area (SLA), vegetative plant height, and seed mass (Westoby, 1998). These traits reflect different strategies in plant dispersal, establishment, persistence and response to disturbances (Díaz et al., 2016), and are related to ecosystem functions such as soil multifunctionality, decomposition rate or herbivory (de Bello et al., 2010; Peco, Navarro, Carmona, Medina, \& Marques, 2017; Valencia et al., 2018). We estimated the average value for each trait and species after excluding outliers (observations $>3$ sd away from the species' mean). The averages for each species and trait combination were calculated first within individuals (if multiple measurements were taken from a single individual), then within datasets (if multiple individuals were measured in the same location) and finally within species (if multiple individuals were measured in various locations). In calculations of functional structure we only considered species for which we had complete trait infomation, and removed the assemblages when less than $80 \%$ of the species in that assemblage had trait information associated with them. This left a total of 335 species and 1235 assemblages (i.e. sampling points) distributed in 786 fields within 261 farms in the nine study areas. 
Preliminary data exploration showed that the raw data for seed mass and plant height were not normally distributed, so these variables were log-transformed to attain normal distributions. In each assemblage, we used species richness (estimated as the number of species found in each sampling point) as an indicator of taxonomic diversity, and the average trait value (community weighted mean; CWM) for each trait as an indicator of the most frequent trait values, i.e. the functional composition of assemblages (Carmona, Mason, Azcárate, \& Peco, 2015). Further, we calculated several indicators of functional diversity in each assemblage. We used for this the trait probablity density (TPD) approach, which estimates probabilistic functional niches of species and assemblages, which allow afterwards to estimate several aspects of functional diversity (Carmona, Bello, Mason, \& Lepš, 2019; Carmona, de Bello, Mason, \& Lepš, 2016). Since information on intraspecific trait variability was not available, the center of each TPDs function was defined by the coordinates corresponding to its three trait values, and the variance around it was estimated by means of a fixed kernel bandwidth of 0.5 SD for each trait (following Lamanna et al., 2014). Subsequently, we estimated the TPD function of each sampling point (TPDc) by calculating a weighted average of the TPDs functions of the species in each assemblage, using their relative frequency as a weighting factor (see Carmona et al., 2016 for further details). The value of a TPDc function for each particular combination of trait values reflects the probability of observing that combination in the considered assemblage.

We then used the R package 'TPD' (Carmona, 2019; Carmona et al., 2019) to estimate several indicators of functional diversity in the assemblages, including functional richness (the amount of functional space occupied by the assemblage; Fig. 1a), functional evenness (the evenness in the distribution of the abundance in the functional trait space; Fig. 1b),

217 functional divergence (the degree to which the pooled abundance is distributed toward the 218 extremes of the functional volume of the assemblage; Fig. 1c), and functional redundancy 219 (the degree to which the species in an assemblage occupy the same functional space; Fig. 1d). All these indices are described in detail in Carmona et al. (2019). Both functional richness and functional redundancy are related to species richness (since both indices can only increase as new species are added). To quantify the patterns of association between these indices and to ensure independence from the taxonomic aspect of diversity, we additionally performed two different corrections. In the case of functional richness, we compared the observed value in each assemblage for this index with the values expected under random species assembly processes; for this, we performed a matrix-swap null model, randomizing 
species within each study area while keeping both row and column sums fixed (permatswap function from the R package 'vegan'; Oksanen et al., 2018). We estimated 500 null values of functional richness for each assemblage using this procedure, and then compared them with the observed value using Standardized Effect Sizes (SES; Carmona et al., 2015; Micó et al., 2020). In the case of functional redundancy, the upper bound of this measure in an assemblage can also be calculated from species richness minus one (S-1); in order to break this correlation we expressed redundancy in relative terms by dividing it by S-1 (Carmona et al., 2019).

235

\section{Statistical analyses}

237

We examined the relationship between the assemblage level metrics (species richness, functional CWM of the three traits, functional richness, evenness, divergence and redundancy) and agricultural intensity at the field and landscape levels by means of mixed models (with a Poisson distribution in the case of species richness), using the 'lme4' $\mathrm{R}$ package (Bates, Mächler, Bolker, \& Walker, 2015). The models included both intensity indicators (scores in the PCA axes) as explanatory variables, and field nested in farm nested in study area as random factors, to account for the hierarchical study design. We explored whether the reponses to agricultural intensity were similar across study areas for each response variable by fitting a model with random slopes for both intensity indicators as random slopes within study areas and a model without these random slopes. We compared these two models with diferent random structures by means of AIC, and kept for each variable the model with the lowest AIC score (Zuur, Ieno, Walker, Saveliev, \& Smith, 2009). For all selected models, we estimated conditional and marginal coefficients of determination using the function r.squaredGLMM from the MuMIn package (Barton, 2016; Nakagawa, Johnson, \& Schielzeth, 2017). Conditional $\mathrm{R}^{2}$ reflects the variance explained by the entire model, including both fixed and random effects, whereas marginal $\mathrm{R}^{2}$ reflects the variance explained only by the fixed effects, i.e. intensity at the field and landscape levels.

\section{Results}

All the models including random slopes for intensification had higher AIC values than the models without the random slopes (Table S2). Accordingly, all reported results correspond to the models without random slopes. 
260 Agricultural intensity had a strong influence on species richness (marginal $\mathrm{R}^{2}=0.29$ ). In particular, field-level intensity markedly reduced species richness, with a three-fold reduction in the number of species observed in the assemblages from the least-intensified to the mostintensified fields (poisson regression $\beta_{\text {Field }} \pm \mathrm{SE}=-0.38 \pm 0.03$; $\mathrm{p}<0.001$; Fig. 2). Intensity at the landscape level had a much smaller but still highly significant negative effect $\left(\beta_{\text {Landscape }}=\right.$ $-0.08 \pm .03 ; p=0.002 ;$ Fig. 2 ) reducing observed species richness. We did not observe a significant interaction between the two levels of intensification $(\mathrm{p}=0.19)$.

\section{Functional composition}

Agricultural intensity significantly affected the average values of the three selected traits. However, it explained low amounts of variation in all cases (marginal $\mathrm{R}^{2}$ was between 0.01 and 0.02), with the random effects explaining a much larger proportion (conditional $\mathrm{R}^{2}$ between 0.67 and 0.73 ). Similarly, the proportion of variation explained by each level of the random factor differed markedly between traits, with differences between fields and between farms accounting for a majority of variability in plant height (ca 25\% each level), whereas most of the variation in SLA and seed mass was between study areas (42\% and 39\%, respectively). Plant height decreased with field-level intensity $\left(\beta_{\text {Field }}=-0.18 \pm 0.06 ; p=0.003\right)$, whereas average SLA values generally increased ( $\beta_{\text {Field }}=0.14 \pm 0.05 ; p=0.006 ;$ Fig. 3 ). However, landscape level intensity did not have any important effect on these two traits. In contrast, seed mass decreased with intensification at the landscape level, but showed no patterns at the field scale $\left(\beta_{\text {Landscape }}=-0.11 \pm 0.05 ; p=0.016 ;\right.$ Fig. 3$)$.

Functional diversity

As expected, functional richness followed patterns similar to species richness (marginal $\left.\mathrm{R}^{2}=0.23\right)$, decreasing with intensity at the field $\left(\beta_{\text {Field }}=-103.14 \pm 8.98 ; \mathrm{p}<0.001\right)$ and at the landscape scale $\left(\beta_{\text {Landscape }}=-23.60 \pm 8.49 ; p=0.006 ;\right.$ Fig. 3$)$. However, after removing the effect of species richness by means of the null model (functional richness SES), landscapelevel intensity ceased to have an effect (Fig. S2). In contrast to raw functional richness, functional richness SES increased with intensity at the field level, but overall the effects of intensity on this variable were very small (marginal $R^{2}=0.01$; Fig. S2). Agricultural intensity had a moderate effect on functional evenness (marginal $\mathrm{R}^{2}=0.08$; Fig. 3 ), so that functional eveness increased with intensity at the field scale $\left(\beta_{\text {Field }}=0.008 \pm 0.001 ; p<0.001\right)$, but not at the landscape scale. Similarly, functional divergence increased with intensity at the field scale 
$291 \quad\left(\beta_{\text {Field }}=0.02 \pm 0.003 ; \mathrm{p}<0.001\right)$ and was not significantly related to intensity at the landscape 292 scale. Functional redundancy decreased substantially with field scale intensity ( $\beta_{\text {Field }}=-$

$2930.78 \pm 0.06 ; \mathrm{p}<0.001$; Fig. 3), but was not affected by intensity at the landscape scale. This 294 negative effect of intensification at the field scale remained significant after correcting for the 295 effect of species richness on redundancy (relative redundancy; Fig. S3).

\section{Discussion}

298 Our results show that agricultural intensification had consistently negative effects on the 299 diversity of arable weeds assemblages of European cereal-dominated agroecosystems and 300 that this effect was stronger at local field scales than at the landscape scale. Despite the strong decline of taxonomic diversity associated with agricultural intensification (Fig. 2), we found much weaker effects on the functional structure of assemblages (evidenced by the generally low marginal $\mathrm{R}^{2}$ values; Figs 3 and 4), due to the high levels of functional redundancy among species that buffered the effects of species loss. Overall, intensification selected for species with ruderal strategies (low stature, high SLA, light seeds; Pierce et al., 2017), so that these traits were more prevalent in assemblages subject to intensification. Ultimately, this selection contributes to lower functional redundancy. These results depended strongly on the level at which intensification was considered: we found evidence supporting the idea that intensification affects weeds diversity mostly through selection operating at the local field scale. Nonetheless, intensification at the landscape scale also had a negative effect on the average seed mass of weeds assemblages, suggesting that species with poor dispersal abilities are selected against in very intensified landscapes.

313 The relevance of spatial scale remains vitally important for how we manage conservation 314 interventions in agricultural landscapes (Emmerson et al., 2016; Petit et al., 2016; Tscharntke et al., 2005). For example, previous work suggests that the most important scale for consideration depends on the mobility of the taxonomic group under study. Whereas birds

317 (Guerrero et al., 2012), carabids (Winqvist et al., 2014) or wild bees (Happe et al., 2018) are 318 primarily influenced by landscape factors, weed diversity seems to be more strongly determined by field-scale factors (Carmona et al., 2017; Guerrero et al., 2014). However, some recent studies have underscored the importance of the larger-scale factors for arable weeds diversity, either independently or by modulating the effects of local factors (Gabriel et al., 2010; Henckel, Börger, Meiss, Gaba, \& Bretagnolle, 2015; Petit et al., 2016; Tuck et al., 2014). Our results do not support this view, since intensification at the landscape scale had 
little influence on local species richness, and the interaction with the field scale was not significant for any of the studied variables. The contrasting results obtained from different studies could be due to factors such as the position within the field of the considered samples, or the different ways in which landscape level intensification was measured between studies. For example, the influence of landscape scale processes is known to decrease as the distance from the edge of the field increases (José-María, Armengot, Blanco-Moreno, Bassa, \& Sans, 2010), and the plots considered in this study where relatively far from field edges. Further, whereas other studies emcompass factors related to field management, but acting at landscape level, such as the proportion of organic fields (Petit et al., 2016), our landscape-level variables measure exclusively landscape structure or complexity based on semi-natural elements (Billeter et al., 2007b).

Our results show that the two considered aspects of intensification had different effects on vegetative (SLA and plan height) and regenerative (seed mass) traits. Field level intensification seemed to select for phenotypes characterized by smaller stature and higher SLA. Plants with low height are better able to cope with physical disturbance associated with tillage (Rota, Manzano, Carmona, Malo, \& Peco, 2017; Westoby, 1998), whereas high SLA values are associated with higher relative growth rates (Shipley, 2006). Together, these traits allow plants to complete their life cycles quickly, hence reducing competition with the crop vegetation (Guerrero et al., 2014), and being able to complete their full life cycle before harvest. Further, herbaceous species with high SLA are better adapted to shade conditions and high supplies of nutrients (Westoby, 1998). Although some studies have reported no relationship between intensification and these traits (Fried, Kazakou, \& Gaba, 2012; Guerrero et al., 2014), both smaller stature and higher SLA are frequently found in response to agricultural intensification (Kazakou et al., 2016; Solé-Senan, Juárez-Escario, Robleño, Conesa, \& Recasens, 2017), in agreement with the expectation that this process selects for ruderal strategies. In this line, it is important to remark that higher $\mathrm{N}$ availability is associated to higher SLA values due to the effect of intraspecific variability (He, Chen, Zhao, Cornelissen, \& Chu, 2018), so that local measurements should be preferable to assess the effect of intensification on functional diversity. However, the relative importance of considering local trait values, which is critical at local scales (Carmona, Rota, Azcárate, \& Peco, 2015), decreases as spatial scale increases (Albert, Grassein, Schurr, Vieilledent, \& Violle, 2011), as is the case of the present study. The fact that species rankings considering traits from databases and local measurements are similar (Kazakou et al. 2014), suggests that our results should be robust to this effect. 
359 Because of the loss of landscape complexity in intensively managed landscapes, arable weeds assemblages become more isolated and disconnected from seed sources (e.g. grasslands, fallows and field borders) and tend to have lower propagule pressure. Consequently, the negative effect of landscape level intensification on species richness observed in this study is likely to be due to this isolation effect (Damschen et al., 2019). In the present study, average seed mass decreased with intensification at the landscape scale, probably due to the higher dispersal ability of species with small seeds. Small seeds tend to disperse further (Cornelissen et al., 2003), and tend to persist longer in the soil seed bank (Hernández Plaza, Navarrete, \& González-Andejar, 2015). Additionally, given equivalent reproductive investment, plants with small seeds produce more seeds (Jakobsson \& Eriksson, 2000). For these reasons, plants with smaller seeds might have a dispersion advantage in intensively managed landscapes and might persist longer in the assemblages. Similar patterns have been observed in other habitats (reviewed in Vellend, 2016), but this is, to the best of our knowledge, the first observation in agricultural landscapes.

373 The reduction in species richness associated with intensification was accompanied by a similar reduction in the functional space occupied by these arable weeds assemblages. The species-rich assemblages at the least intensified end of the gradient had lower functional evenness and divergence than the assemblages from more intensified fields. This means that the distribution of trait values in the more diverse assemblages tended to be more clumped (see Fig. 1). This interpretation was further confirmed by the observed reduction in functional redundancy with intensification. Overall, we found clear evidence showing that agricultural intensification acts by selecting against (or at least reducing the abundance of) functionally redundant species. This in turn implies that the functional structure of these systems can resist, relatively well, the loss of species associated with agricultural intensification (Carmona et al., 2017). However, the observed reductions in redundancy were higher than expected for similar levels of species loss (Fig. S3), which suggests that functionally unique species are more sensitive to intensification than species with more commonly occuring trait values. The extirpation of more unique species could have profound impacts if they are also important for ecosystem functioning, as found in other systems (Mouillot et al., 2013). Overall, lower functional redundancy due to intensification is likely to increase the vulnerability of these systems to other impacts, such as climate change (Rader, Bartomeus, Tylianakis, \& Laliberté, 2014) or biological invasions (Galland et al., 2019; Loiola et al., 2018). 
391 European arable weeds communities are threatened by agricultural intensification (Weisser et al., 2017). Their decline weakens fundamental ecosystem functions (Knops et al., 1999), thus compromising the provision of key ecosystem services, and even the profitability of certain productive activities associated with agriculture (Emmerson et al., 2016; Gaba, Gabriel,

395 Chadœuf, Bonneu, \& Bretagnolle, 2016). Our results highlight the need to extensify field-

396 level agricultural management throughout Europe, i.e. reduction of input amounts and

397 frequency of ploughing and other mechanical operations, and longer rotation cycles that

398 incorporate fallow periods. Arable weeds communities would also benefit from the promotion of higher landscape complexity, which could be achieved through maintaining or developing extensive use of some cereal fields (e.g. by promoting organic agriculture or by using fallows), and would support species with poor dispersal abilities. Although dynamic interpretations should be made carefully when using space-for-time substitution studies (Damgaard, 2019), the use of data collected following a standardized protocol across a continental scale, and the selection of fields with relatively homogenous characteristics (crop type, climate, soils) within study areas, make the results of this study particularly valuable. Our study provides expectations about the changes in farmland plant community structure and functional composition in the face of increasing agriculture intensification across Europe (see Table 2). This knowledge could be used to guide and inform management interventions at the appropriate spatial scales aimed at preventing futher species loss and mitigating potential impacts on ecosystem services linked to global change processes.

\section{Data availability statement}

413 Data have been deposited in the Dryad Digital Repository,

414 https://doi.org/10.5061/dryad.2rbnzs7k5 (Carmona et al. 2020).

\section{References}

417 Aavik, T., \& Liira, J. (2010). Quantifying the effect of organic farming, field boundary type 418 and landscape structure on the vegetation of field boundaries. Agriculture, Ecosystems and Environment, 135(3), 178-186. doi: 10.1016/j.agee.2009.09.005

Albert, C. H., Grassein, F., Schurr, F. M., Vieilledent, G., \& Violle, C. (2011). When and how should intraspecific variability be considered in trait-based plant ecology? Perspectives in Plant Ecology, Evolution and Systematics, 13(3), 217-225. doi: 10.1016/j.ppees.2011.04.003 
Barton, K. (2016). MuMIn: Multi-Model Inference. Retrieved April 1, 2018, from https://cran.r-project.org/package=MuMIn

Bates, D., Mächler, M., Bolker, B., \& Walker, S. (2015). Fitting Linear Mixed-Effects Models Using Ime4. Journal of Statistical Software, 67(1), 1-48. doi: 10.18637/jss.v067.i01

Billeter, R., Liira, J., Bailey, D., Bugter, R., Arens, P., Augenstein, I., ... Edwards, P. J. (2007a). Indicators for biodiversity in agricultural landscapes: a pan-European study. Journal of Applied Ecology, 45(1), 141-150. doi: 10.1111/j.1365-2664.2007.01393.x Billeter, R., Liira, J., Bailey, D., Bugter, R., Arens, P., Augenstein, I., ... Edwards, P. J. (2007b). Indicators for biodiversity in agricultural landscapes: a pan-European study. Journal of Applied Ecology, 45(1), 141-150. doi: 10.1111/j.1365-2664.2007.01393.x

Brooks, D. R., Storkey, J., Clark, S. J., Firbank, L. G., Petit, S., \& Woiwod, I. P. (2012). Trophic links between functional groups of arable plants and beetles are stable at a national scale. Journal of Animal Ecology, 81(1), 4-13. doi: 10.1111/j.13652656.2011.01897.x

Butler, S. J., Mattison, E. H. A., Glithero, N. J., Robinson, L. J., Atkinson, P. W., Gillings, S., ... Norris, K. (2010). Resource availability and the persistence of seed-eating bird populations in agricultural landscapes : a mechanistic modelling approach. Journal of Applied Ecology, 47(1), 67-75. doi: 10.1111/j.1365-2664.2009.01750.x

Cadotte, M. W., Carscadden, K., \& Mirotchnick, N. (2011). Beyond species: functional diversity and the maintenance of ecological processes and services. Journal of Applied Ecology, 48, 1079-1087. doi: 10.1111/j.1365-2664.2011.02048.x

Carmona, C. P. (2019). TPD: methods for measuring functional diversity based on Trait Probability Density.

Carmona, C. P., Bello, F., Mason, N. W. H., \& Lepš, J. (2019). Trait probability density ( TPD ): measuring functional diversity across scales based on TPD with R. Ecology, 100(12), e02876. doi: 10.1002/ecy.2876

Carmona, C. P., de Bello, F., Mason, N. W. H., \& Lepš, J. (2016). Traits Without Borders : Integrating Functional Diversity Across Scales. Trends in Ecology \& Evolution, 31(5), 382-394. doi: 10.1016/j.tree.2016.02.003

Carmona, C. P., Guerrero, I., Morales, M. B., Oñate, J. J., \& Peco, B. (2017). Assessing vulnerability of functional diversity to species loss: a case study in Mediterranean agricultural systems. Functional Ecology, 31(2). doi: 10.1111/1365-2435.12709

Carmona, C. P., Guerrero, I., Peco, B, Morales, M. B., Oñate, J. J., Pärt, T., Tscharntke, T., 
Liira, J., Aavik, T., Emmerson, M., Berendese, F., Ceryngier, P., Bretagnolle, V., Weisser, W. W., \& Bengtsson, J. (2020), Agricultural intensification reduces plant taxonomic and functional diversity across European arable systems., v2, Dryad, Dataset, https://doi.org/10.5061/dryad.2rbnzs7k5

Carmona, C. P., Mason, N. W. H., Azcárate, F. M., \& Peco, B. (2015). Inter-annual fluctuations in rainfall shift the functional structure of Mediterranean grasslands across gradients of productivity and disturbance. Journal of Vegetation Science, 26(3), 538551. doi: $10.1111 /$ jvs. 12260

Carmona, C. P., Rota, C., Azcárate, F. M., \& Peco, B. (2015). More for less: Sampling strategies of plant functional traits across local environmental gradients. Functional Ecology, 29(4), 579-588. doi: 10.1111/1365-2435.12366

Chamberlain, D. E., Fuller, R. J., Bunce, R. G. H., Duckworth, J. C., \& Shrubb, M. (2000). Changes in the abundance of farmland birds in relation to the timing of agricultural intensification in England and Wales. Journal of Applied Ecology, 37(5), 771-788. doi: 10.1046/j.1365-2664.2000.00548.x

Cornelissen, J. H. C., Lavorel, S., Garnier, E., Díaz, S., Buchmann, N., Gurvich, D. E., ... Poorter, H. (2003). A handbook of protocols for standardised and easy measurement of plant functional traits worldwide. Australian Journal of Botany, 335-380.

Damgaard, C. (2019). A Critique of the Space-for-Time Substitution Practice in Community Ecology. Trends in Ecology and Evolution, Vol. 34, pp. 416-421. doi: 10.1016/j.tree.2019.01.013

Damschen, E. I., Brudvig, L. A., Burt, M. A., Fletcher, R. J., Haddad, N. M., Levey, D. J., ... Tewksbury, J. J. (2019). Ongoing accumulation of plant diversity through habitat connectivity in an 18-year experiment. Science, 365(6460), 1478-1480. doi: $10.1126 /$ science.aax 8992

de Bello, F., Lavorel, S., Díaz, S., Harrington, R., Cornelissen, J. H. C., Bardgett, R. D., ... Harrison, P. A. (2010). Towards an assessment of multiple ecosystem processes and services via functional traits. Biodiversity and Conservation, 19, 2873-2893. doi: 10.1007/s10531-010-9850-9

Díaz, S., Kattge, J., Cornelissen, J. H. C., Wright, I. J., Lavorel, S., Dray, S., ... Gorné, L. D. (2016). The global spectrum of plant form and function. Nature, 529, 167-171. doi: 10.1038/nature16489

Donald, P. F., Sanderson, F. J., Burfield, I. J., \& van Bommel, F. P. J. (2006). Further evidence of continent-wide impacts of agricultural intensification on European farmland 
492

493

494

495

496

497

498

499

500

501

502

503

504

505

506

507

508

509

510

511

512

513

514

515

516

517

518

519

520

521

522

523

524

525

birds, 1990-2000. Agriculture, Ecosystems and Environment, 116(3-4), 189-196. doi: 10.1016/j.agee.2006.02.007

Ebeling, A., Klein, A.-M., Weisser, W. W., \& Tscharntke, T. (2012). Multitrophic effects of experimental changes in plant diversity on cavity-nesting bees, wasps, and their parasitoids. Oecologia, 169(2), 453-465. doi: 10.1007/s00442-011-2205-8

Emmerson, M., Morales, M. B., Oñate, J. J., Batáry, P., Berendse, F., Liira, J., ... Bengtsson, J. (2016). How Agricultural Intensification Affects Biodiversity and Ecosystem Services. In Advances in Ecological Research (Vol. 55, pp. 43-97). doi: 10.1016/bs.aecr.2016.08.005

Eraud, C., Cadet, E., Powolny, T., Gaba, S., Bretagnolle, F., \& Bretagnolle, V. (2015). Weed seeds, not grain, contribute to the diet of wintering skylarks in arable farmlands of Western France. European Journal of Wildlife Research, 61(1), 151-161. doi: 10.1007/s10344-014-0888-y

Eurostat. (2018). 2018. Agriculture, forestry and fishery statistics. Luxembourg.

Evans, D. M., Pocock, M. J. O., Brooks, J., \& Memmott, J. (2011). Seeds in farmland foodwebs: Resource importance, distribution and the impacts of farm management. Biological Conservation, 144(12), 2941-2950. doi: 10.1016/j.biocon.2011.08.013

Flohre, A., Fischer, C., Aavik, T., Bengtsson, J., Berendse, F., Bommarco, R., ... Tscharntke, T. (2011). Agricultural intensification and biodiversity partitioning in European landscapes comparing plants, carabids, and birds. Ecological Applications, 21(5), 17721781.

Flynn, D. F. B., Gogol-Prokurat, M., Nogeire, T., Molinari, N., Richers, B. T., Lin, B. B., ... DeClerck, F. (2009). Loss of functional diversity under land use intensification across multiple taxa. Ecology Letters, 12(1), 22-33. doi: 10.1111/j.1461-0248.2008.01255.x

Fried, G., Kazakou, E., \& Gaba, S. (2012). Trajectories of weed communities explained by traits associated with species' response to management practices. Agriculture, Ecosystems and Environment, 158, 147-155. doi: 10.1016/j.agee.2012.06.005

Gaba, S., Gabriel, E., Chadœuf, J., Bonneu, F., \& Bretagnolle, V. (2016). Herbicides do not ensure for higher wheat yield, but eliminate rare plant species. Scientific Reports, 6(1), 30112. doi: 10.1038/srep30112

Gabriel, D., Sait, S. M., Hodgson, J. A., Schmutz, U., Kunin, W. E., \& Benton, T. G. (2010). Scale matters: the impact of organic farming on biodiversity at different spatial scales. Ecology Letters, 13(7), 858-869. doi: 10.1111/j.1461-0248.2010.01481.x

Gabriel, D., Thies, C., \& Tscharntke, T. (2005). Local diversity of arable weeds increases 
with landscape complexity. Perspectives in Plant Ecology, Evolution and Systematics, 7(2), 85-93. doi: 10.1016/j.ppees.2005.04.001

Galland, T., Adeux, G., Dvořáková, H., E-Vojtkó, A., Orbán, I., Lussu, M., ... Götzenberger, L. (2019). Colonization resistance and establishment success along gradients of functional and phylogenetic diversity in experimental plant communities. Journal of Ecology, 107(5), 2090-2104. doi: 10.1111/1365-2745.13246

Geiger, F., Bengtsson, J., Berendse, F., Weisser, W. W., Emmerson, M., Morales, M. B., ... Inchausti, P. (2010). Persistent negative effects of pesticides on biodiversity and biological control potential on European farmland. Basic and Applied Ecology, 11(2), 97-105. doi: 10.1016/j.baae.2009.12.001

Gonthier, D. J., Ennis, K. K., Farinas, S., Hsieh, H.-Y., Iverson, A. L., Batary, P., ... Perfecto, I. (2014). Biodiversity conservation in agriculture requires a multi-scale approach. Proceedings of the Royal Society B: Biological Sciences, 281(1791), 20141358-20141358. doi: 10.1098/rspb.2014.1358

Green, R. E., Cornell, S. J., Scharlemann, J. P. W., \& Balmford, A. (2005). Farming and the Fate of Wild Nature. Science, 307(5709).

Guerrero, I., Carmona, C. P., Morales, M. B., Oñate, J. J., \& Peco, B. (2014). Non-linear responses of functional diversity and redundancy to agricultural intensification at the field scale in Mediterranean arable plant communities. Agriculture, Ecosystems \& Environment, 195, 36-43. doi: 10.1016/j.agee.2014.05.021

Guerrero, I., Morales, M. B., Oñate, J. J., Geiger, F., Berendse, F., Snoo, G. de, ... Tscharntke, T. (2012). Response of ground-nesting farmland birds to agricultural intensification across Europe: Landscape and field level management factors. Biological Conservation, 152, 74-80. doi: 10.1016/j.biocon.2012.04.001

Happe, A. K., Riesch, F., Rösch, V., Gallé, R., Tscharntke, T., \& Batáry, P. (2018). Smallscale agricultural landscapes and organic management support wild bee communities of cereal field boundaries. Agriculture, Ecosystems and Environment, 254, 92-98. doi: 10.1016/j.agee.2017.11.019

He, D., Chen, Y., Zhao, K., Cornelissen, J. H. C., \& Chu, C. (2018). Intra- and interspecific trait variations reveal functional relationships between specific leaf area and soil niche within a subtropical forest. Annals of Botany, 121(6), 1173-1182.

Henckel, L., Börger, L., Meiss, H., Gaba, S., \& Bretagnolle, V. (2015). Organic fields sustain weed metacommunity dynamics in farmland landscapes. Proceedings of the Royal Society of London B: Biological Sciences, 282(1808). 
560

561

562

563

564

565

566

567

568

569

570

571

572

573

574

575

576

577

578

579

580

581

582

583

584

585

586

587

588

589

590

591

592

593

Hernández Plaza, E., Navarrete, L., \& González-Andújar, J. L. (2015). Intensity of soil disturbance shapes response trait diversity of weed communities: The long-term effects of different tillage systems. Agriculture, Ecosystems and Environment, 207, 101-108. doi: 10.1016/j.agee.2015.03.031

Hevia, V., Carmona, C. P., Azcárate, F. M., Torralba, M., Alcorlo, P., Ariño, R., ... González, J. A. (2016). Effects of land use on taxonomic and functional diversity: a cross-taxon analysis in a Mediterranean landscape. Oecologia, 181(4). doi: $10.1007 / \mathrm{s} 00442-015-3512-2$

Jakobsson, A., \& Eriksson, O. (2000). A comparative study of seed number, seed size, seedling size and recruitment in grassland plants. Oikos, 88(3), 494-502. doi: 10.1034/j.1600-0706.2000.880304.x

José-María, L., Armengot, L., Blanco-Moreno, J. M., Bassa, M., \& Sans, F. X. (2010). Effects of agricultural intensification on plant diversity in Mediterranean dryland cereal fields. Journal of Applied Ecology, 47(4), 832-840. doi: 10.1111/j.13652664.2010.01822.x

Kattge, J., Bönisch, G., Díaz, S., Lavorel, S., Prentice, I. C., Leadley, P., ... Wirth, C. (2020). TRY plant trait database - enhanced coverage and open access. Global Change Biology, 26(1), 119-188. doi: 10.1111/gcb.14904

Kazakou, E., Fried, G., Richarte, J., Gimenez, O., Violle, C., \& Metay, A. (2016). A plant trait-based response-and-effect framework to assess vineyard inter-row soil management. Botany Letters, 163(4), 373-388. doi: 10.1080/23818107.2016.1232205

Knops, J. M. H., Tilman, D., Haddad, N. M., Naeem, S., Mitchell, C. E., Haarstad, J., ... Groth, J. (1999). Effects of plant species richness on invasion dynamics, disease outbreaks, insect abundances and diversity. Ecology Letters, 2(5), 286-293. doi: 10.1046/j.1461-0248.1999.00083.x

Laliberté, E., Wells, J. A., Declerck, F., Metcalfe, D. J., Catterall, C. P., Queiroz, C., ... Mayfield, M. M. (2010). Land-use intensification reduces functional redundancy and response diversity in plant communities. Ecology Letters, 13(1), 76-86. doi: 10.1111/j.1461-0248.2009.01403.x

Lamanna, C., Blonder, B., Violle, C., Kraft, N. J. B., Sandel, B., Šímová, I., ... Enquist, B. J. (2014). Functional trait space and the latitudinal diversity gradient. Proceedings of the National Academy of Sciences, 111(38), 13745-13750. doi: 10.1073/pnas.1317722111 Loiola, P. P., de Bello, F., Chytrý, M., Götzenberger, L., Carmona, C. P., Pyšek, P., \& Lososová, Z. (2018). Invaders among locals: alien species decrease phylogenetic and 
functional diversity while increasing dissimilarity among native community members. Journal of Ecology. doi: 10.1111/1365-2745.12986

Martin, E. A., Dainese, M., Clough, Y., Báldi, A., Bommarco, R., Gagic, V., ... SteffanDewenter, I. (2019). The interplay of landscape composition and configuration: new pathways to manage functional biodiversity and agroecosystem services across Europe. Ecology Letters, 22(7), 1083-1094. doi: 10.1111/ele.13265

Matson, P. A., Parton, W. J., Power, A. G., \& Swift, M. J. (1997). Agricultural Intensification and Ecosystem Properties. Science, 277(5325), 504-509.

Micó, E., Ramilo, P., Thorn, S., Müller, J., Galante, E., \& Carmona, C. P. (2020). Contrasting functional structure of saproxylic beetle assemblages associated to different microhabitats. Scientific Reports, 10(1), 1520. doi: 10.1038/s41598-020-58408-6

Mouillot, D., Bellwood, D. R., Baraloto, C., Chave, J., Galzin, R., Harmelin-Vivien, M., ... Thuiller, W. (2013). Rare species support vulnerable functions in high-diversity ecosystems. PLoS Biology, 11(5), e1001569. doi: 10.1371/journal.pbio.1001569

Nakagawa, S., Johnson, P. C. D., \& Schielzeth, H. (2017). The coefficient of determination $R$ 2 and intra-class correlation coefficient from generalized linear mixed-effects models revisited and expanded. Journal of The Royal Society Interface, 14(134), 20170213. doi: 10.1098/rsif.2017.0213

Oksanen, J., Blanchet, F. G., Kindt, R., Legendre, P., Minchin, P. R., O’Hara, R. B., ... Wagner, H. (2018), vegan: Community Ecology Package.

Peco, B., Navarro, E., Carmona, C. P., Medina, N. G., \& Marques, M. J. (2017). Effects of grazing abandonment on soil multifunctionality: The role of plant functional traits. Agriculture, Ecosystems \& Environment, 249(April), 215-225. doi: 10.1016/j.agee.2017.08.013

Petit, S., Gaba, S., Grison, A. L., Meiss, H., Simmoneau, B., Munier-Jolain, N., \& Bretagnolle, V. (2016). Landscape scale management affects weed richness but not weed abundance in winter wheat fields. Agriculture, Ecosystems and Environment, 223, 41-47. doi: 10.1016/j.agee.2016.02.031

Pierce, S., Negreiros, D., Cerabolini, B. E. L., Kattge, J., Díaz, S., Kleyer, M., ... Tampucci, D. (2017). A global method for calculating plant $\langle\mathrm{scp}\rangle \mathrm{CSR}</ \mathrm{scp}\rangle$ ecological strategies applied across biomes world-wide. Functional Ecology, 31(2), 444-457. doi: $10.1111 / 1365-2435.12722$

Rader, R., Bartomeus, I., Tylianakis, J. M., \& Laliberté, E. (2014). The winners and losers of land use intensification: Pollinator community disassembly is non-random and alters 
functional diversity. Diversity and Distributions, 20(8), 908-917. doi: $10.1111 /$ ddi.12221

Rota, C., Manzano, P., Carmona, C. P., Malo, J. E., \& Peco, B. (2017). Plant community assembly in Mediterranean grasslands: understanding the interplay between grazing and spatio-temporal water availability. Journal of Vegetation Science, 28(1), 149-159. doi:

$$
10.1111 / \text { jvs. } 12470
$$

Scherber, C., Eisenhauer, N., Weisser, W. W., Schmid, B., Voigt, W., Fischer, M., ... Tscharntke, T. (2010). Bottom-up effects of plant diversity on multitrophic interactions in a biodiversity experiment. Nature, 468(7323), 553-556. doi: 10.1038/nature09492

Shipley, B. (2006). Net assimilation rate, specific leaf area and leaf mass ratio: Which is most closely correlated with relative growth rate? A meta-analysis. Functional Ecology, 20(4), 565-574. doi: 10.1111/j.1365-2435.2006.01135.x

Sirami, C., Gross, N., Baillod, A. B., Bertrand, C., Carrié, R., Hass, A., ... Fahrig, L. (2019). Increasing crop heterogeneity enhances multitrophic diversity across agricultural regions. Proceedings of the National Academy of Sciences, 116(33), 16442-16447. doi: 10.1073/pnas.1906419116

Solé-Senan, X. O., Juárez-Escario, A., Robleño, I., Conesa, J. A., \& Recasens, J. (2017). Using the response-effect trait framework to disentangle the effects of agricultural intensification on the provision of ecosystem services by Mediterranean arable plants. Agriculture, Ecosystems and Environment, 247, 255-264. doi:

$$
\text { 10.1016/j.agee.2017.07.005 }
$$

Storkey, J., Meyer, S., Still, K. S., \& Leuschner, C. (2012). The impact of agricultural intensification and land-use change on the European arable flora. Proceedings of the Royal Society B: Biological Sciences, 279(1732), 1421-1429. doi: 10.1098/rspb.2011.1686

Sutherland, S. (2004). What makes a weed a weed: life history traits of native and exotic plants in the USA. Oecologia, 141(1), 24-39. doi: 10.1007/s00442-004-1628-x

Tilman, D., Fargione, J., Wolff, B., D’Antonio, C., Dobson, A., Howarth, R., ... Swackhamer, D. (2001). Forecasting Agriculturally Driven Global Environmental Change. Science, 292(5515).

Tscharntke, T., Klein, A. M., Kruess, A., Steffan-Dewenter, I., \& Thies, C. (2005). Landscape perspectives on agricultural intensification and biodiversity $\hat{a} €$ “ ecosystem service management. Ecology Letters, 8(8), 857-874. doi: 10.1111/j.14610248.2005.00782.x 
662

663

664

665

666

667

668

669

670

671

672

673

674

675

676

677

678

679

680

681

682

683

684

685

686

687

688

Tscharntke, T., Tylianakis, J. M., Rand, T. A., Didham, R. K., Fahrig, L., Batáry, P., ... Westphal, C. (2012, August). Landscape moderation of biodiversity patterns and processes - eight hypotheses. Biological Reviews, Vol. 87, pp. 661-685. doi: 10.1111/j.1469-185X.2011.00216.x

Tuck, S. L., Winqvist, C., Mota, F., Ahnström, J., Turnbull, L. A., \& Bengtsson, J. (2014). Land-use intensity and the effects of organic farming on biodiversity: a hierarchical meta-analysis. Journal of Applied Ecology, 51(3), 746-755. doi: 10.1111/13652664.12219

Valencia, E., Gross, N., Quero, J. L., Carmona, C. P., Ochoa, V., Gozalo, B., ... Maestre, F. T. (2018). Cascading effects from plants to soil microorganisms explain how plant species richness and simulated climate change affect soil multifunctionality. Global Change Biology. doi: 10.1111/gcb.14440

Vellend, M. (2016). The Theory of Ecological Communities. doi: 10.1515/9781400883790

Weisser, W. W., Roscher, C., Meyer, S. T., Ebeling, A., Luo, G., Allan, E., ... Eisenhauer, N. (2017). Biodiversity effects on ecosystem functioning in a 15-year grassland experiment: Patterns, mechanisms, and open questions. Basic and Applied Ecology, 23, 1-73. doi: 10.1016/j.baae.2017.06.002

Westoby, M. (1998). A leaf-height-seed ( LHS ) plant ecology strategy scheme. Plant and Soil, 199, 213-227.

Winqvist, C., Bengtsson, J., Öckinger, E., Aavik, T., Berendse, F., Clement, L. W., ...

Bommarco, R. (2014). Species' traits influence ground beetle responses to farm and landscape level agricultural intensification in Europe. Journal of Insect Conservation, 18(5), 837-846. doi: 10.1007/s10841-014-9690-0

Zuur, A., Ieno, E. N., Walker, N., Saveliev, A. A., \& Smith, G. M. (2009). Mixed Effects Models and Extensions in Ecology with R. In Springer (1st ed.). New York, USA: Springer-Verlag New York. 
689 Table 1. Description of the different agricultural management intensity variables at the field 690 and landscape level used in the study, and their loadings in the selected PCA axes.

\begin{tabular}{|c|c|c|c|c|}
\hline \multicolumn{2}{|l|}{ Variable } & \multirow{2}{*}{$\begin{array}{l}\text { Description } \\
\text { Cereal grain obtained in focal } \\
\text { field (tons/ha) }\end{array}$} & \multirow{2}{*}{$\begin{array}{c}\text { PC1 } \\
\text { (field) } \\
0.86\end{array}$} & \multirow{2}{*}{$\begin{array}{c}\text { PC2 } \\
\text { (landscape) } \\
0.02\end{array}$} \\
\hline Field-level & Yield & & & \\
\hline & $\begin{array}{l}\text { Amount of } \\
\text { herbicide }\end{array}$ & $\begin{array}{l}\text { Total amount of herbicide active } \\
\text { ingredients applied on focal field } \\
\text { (g/ha) }\end{array}$ & 0.75 & 0.19 \\
\hline & N Fertilizer & $\begin{array}{l}\text { Total amount of nitrogen applied } \\
\text { on focal field }(\mathrm{kg} / \mathrm{ha})\end{array}$ & 0.86 & -0.08 \\
\hline \multirow[t]{3}{*}{$\begin{array}{l}\text { Landscape- } \\
\text { level }\end{array}$} & $\begin{array}{l}\text { Mean field } \\
\text { size }\end{array}$ & $\begin{array}{l}\text { Mean size of fields with arable } \\
\text { crops within a } 500 \text { m radius } \\
\text { circle centred on focal field (ha) }\end{array}$ & -0.01 & 0.84 \\
\hline & $\begin{array}{l}\text { Percentage } \\
\text { cover of arable } \\
\text { crops }\end{array}$ & $\begin{array}{l}\text { Percentage area of arable crops } \\
\text { within a } 500 \text { m radius circle } \\
\text { centred on focal field }\end{array}$ & -0.03 & 0.61 \\
\hline & $\begin{array}{l}\text { Focal field } \\
\text { size }\end{array}$ & $\begin{array}{l}\text { Size of each surveyed plot's } \\
\text { focal field (ha) }\end{array}$ & 0.16 & 0.75 \\
\hline
\end{tabular}

691

692 
693 Table 2. Summary of the expected effects of agricultural intensification across Europe on 694 taxonomic diversity, functional composition (community weighted means) and functional 695 diversity considered in this study.

\begin{tabular}{|c|c|c|}
\hline & Field-level & Landscape-level \\
\hline & \multicolumn{2}{|c|}{ TAXONOMIC DIVERSITY } \\
\hline $\begin{array}{l}\text { Species } \\
\text { richness }\end{array}$ & Communities with fewer species & Communities with fewer species \\
\hline \multicolumn{3}{|c|}{ FUNCTIONAL COMPOSITION } \\
\hline Plant height & $\begin{array}{l}\text { Shorter plants with reduced } \\
\text { dispersal ability }\end{array}$ & - \\
\hline SLA & $\begin{array}{l}\text { Faster growing plants (more } \\
\text { vulnerable to predators and } \\
\text { parasites) }\end{array}$ & - \\
\hline Seed mass & 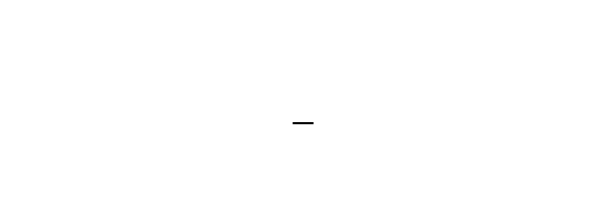 & $\begin{array}{c}\text { Light-seeded plants with high } \\
\text { dispersal but lower seedling } \\
\text { survival }\end{array}$ \\
\hline & \multicolumn{2}{|c|}{ FUNCTIONAL DIVERSITY } \\
\hline Richness & $\begin{array}{l}\text { Communities with reduced } \\
\text { variation in functional trait values }\end{array}$ & $\begin{array}{c}\text { Communities with reduced } \\
\text { variation in functional trait values }\end{array}$ \\
\hline Evenness & $\begin{array}{c}\text { Communities where all trait values } \\
\text { are more evenly represented }\end{array}$ & - \\
\hline Divergence & $\begin{array}{l}\text { Communities where the most } \\
\text { abundant species have different } \\
\text { trait values }\end{array}$ & - \\
\hline Redundancy & $\begin{array}{l}\text { Communities with fewer plants of } \\
\text { similar trait values }\end{array}$ & - \\
\hline
\end{tabular}

696

697 
698 Fig. 1. Illustration of the selected indices of functional structure. In the TPD framewok, the functional structure of an assemblage is expressed as a probability distribution (TPDc) whose value in each point in the functional space reflects the relative abundance of the corresponding trait in the assemblage. For simplicity, all examples are shown in a single dimension ( 1 trait), although in the analyses we have considered a three dimensional functional space. Functional richness (a) indicates the amount of functional space occupied by assemblages; assemblages with higher functional richness (community 2) display a larger variety of trait values. Functional evenness (b) reflects the uniformity in the occupation of the functional space by an assemblage; assemblages with higher functional evenness (community 1) are more similar to an imaginary assemblage occupying the same functional space in a perfectly even way (which are depicted by discontinuous lines). Functional divergence (c) indicates the degree to which the trait abundances in the assemblages are distributed toward the extremes of the part of the functional space they occupy; assemblages with lower functional divergence (assemblage 1) have a higher concentration of traits close to the center of gravity of the assemblage in the trait space. Functional redundancy (d) reflects how much different species (indicated by different colors in the figure) occupy the same functional space. This is estimated by dividing the functional space in a large number of cells $(\mathrm{N})$ and then averaging the number of species (M) that are found within each cell, using the abundance of the total distribution (TPDc) as weighting factor. In the example, the functional space of the assemblage is occupied by an average of 3.87 species; after subtracting 1 from that, functional redundancy expresses the average number of species that could be removed from the assemblage without reducing its functional richness. For formal definitions of these indices see (Carmona et al., 2019, 2016). Fig. 2. Partial regression plots showing the effects of agricultural intensification at the field (left) and landscape (right) levels on weed species richness (mean prediction and 95\% confidence intervals), modelled using a generalized mixed model with Poisson distribution. $\mathrm{R}^{2}$ Marg indicates the proportion of variance explained by the fixed effects (field and landscape level management intensity and their interaction), and $\mathrm{R}^{2}$ Cond includes both fixed and random effects. Colors indicate the study area to which each point belongs (EST: Estonia, FR; France; Go: Germany (Göttingen); IRL: Ireland; JE: Germany (Jena); NL: Netherlands; PL: Poland; SP: Spain; SWE: Sweden). Fig. 3. Partial regression plots showing the effects of agricultural intensification at the field (left) and landscape (right) levels on functional composition modelled using linear mixed models. Functional composition is represented by the community weighted mean of plant 
732 height, specific leaf area (SLA) and seed mass. $\mathrm{R}^{2}$ Marg indicates the proportion of variance 733 explained by the fixed effects (field and landscape level mnagement intensity and their 734 interaction), and $\mathrm{R}^{2}$ Cond includes both fixed and random effects. Colors indicate the study area 735 to which each point belongs (EST: Estonia, FR; France; Go: Germany (Göttingen); IRL:

736 Ireland; JE: Germany (Jena); NL: Netherlands; PL: Poland; SP: Spain; SWE: Sweden).

737 Fig. 4. Partial regression plots showing the effects of agricultural intensification at the field 738 (left) and landscape (right) levels on different indicators of the functional diversity of arable 739 weeds assemblages (functional richness, evenness, divergence and redundancy) modelled 740 using linear mixed models. $\mathrm{R}^{2}$ Marg indicates the proportion of variance explained by the fixed 741 effects (field and landscape level management intensity and their interaction), and $\mathrm{R}^{2}$ Cond 742 includes both fixed and random effects. Colors indicate the study area to which each point 743 belongs (EST: Estonia, FR; France; Go: Germany (Göttingen); IRL: Ireland; JE: Germany 744 (Jena); NL: Netherlands; PL: Poland; SP: Spain; SWE: Sweden). 
a) Functional richness

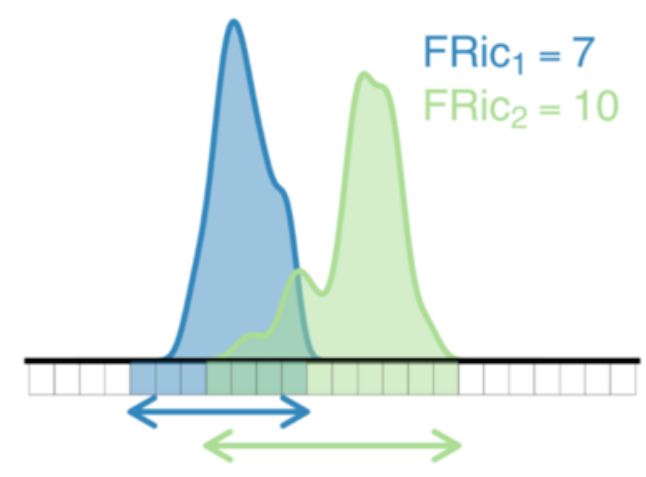

c) Functional divergence

\section{$\mathrm{FDiv}_{1}=0.311$}

$\mathrm{FDiv}_{2}=0.489$

745

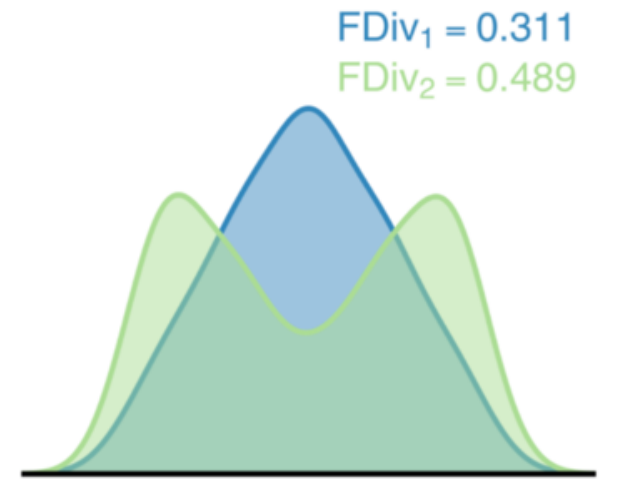

b) Functional evenness

$$
\mathrm{FEve}_{1}=0.709
$$

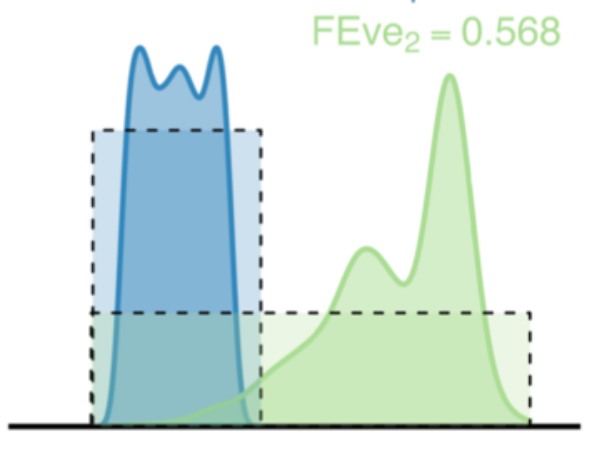

d) Functional redundancy

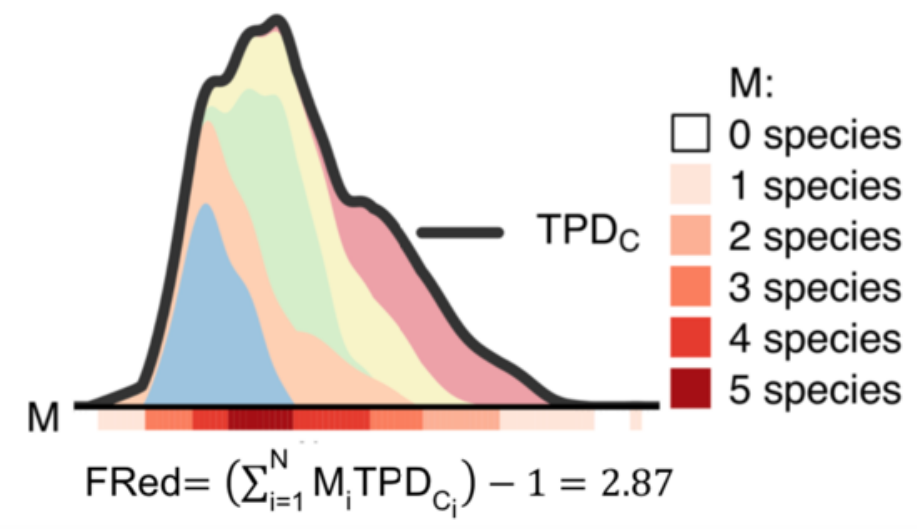

746

Fig. 1 

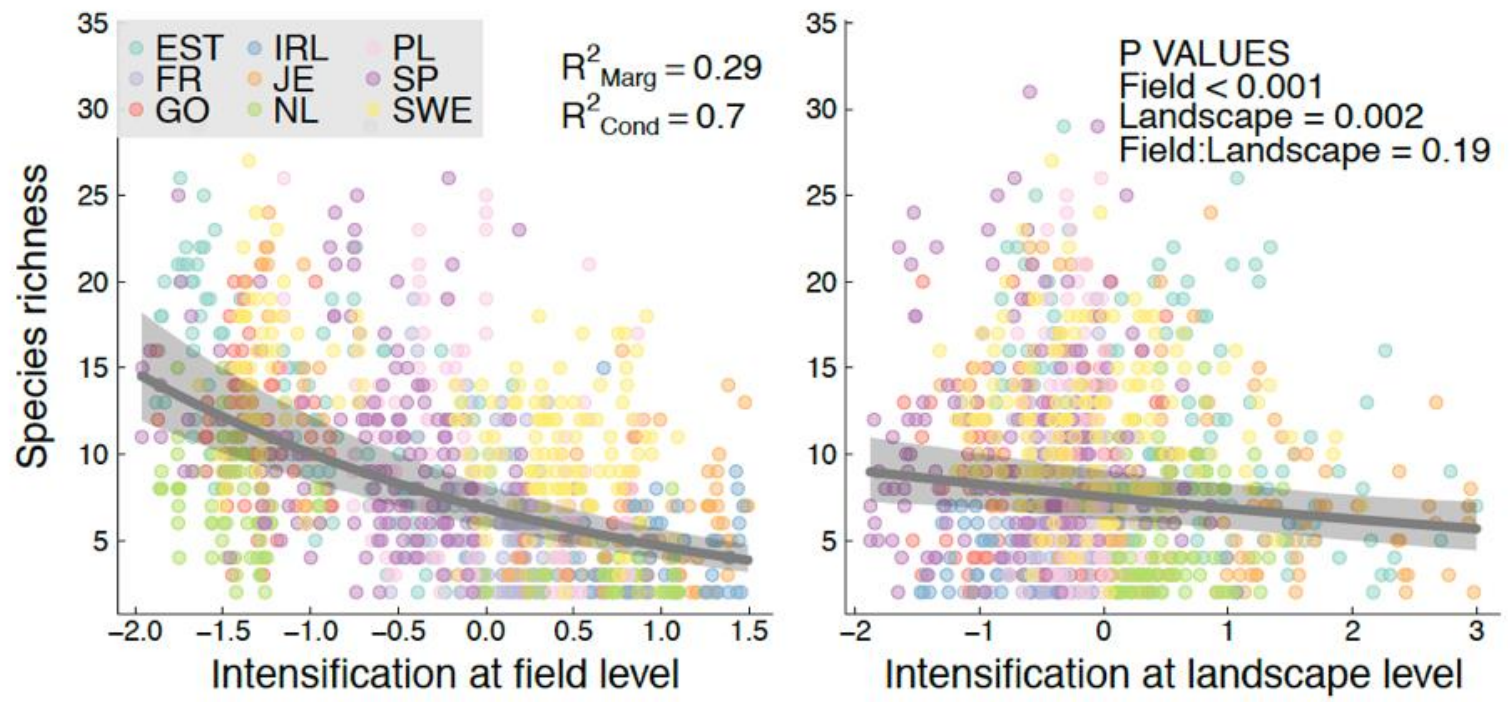

$748 \quad$ Fig. 2 

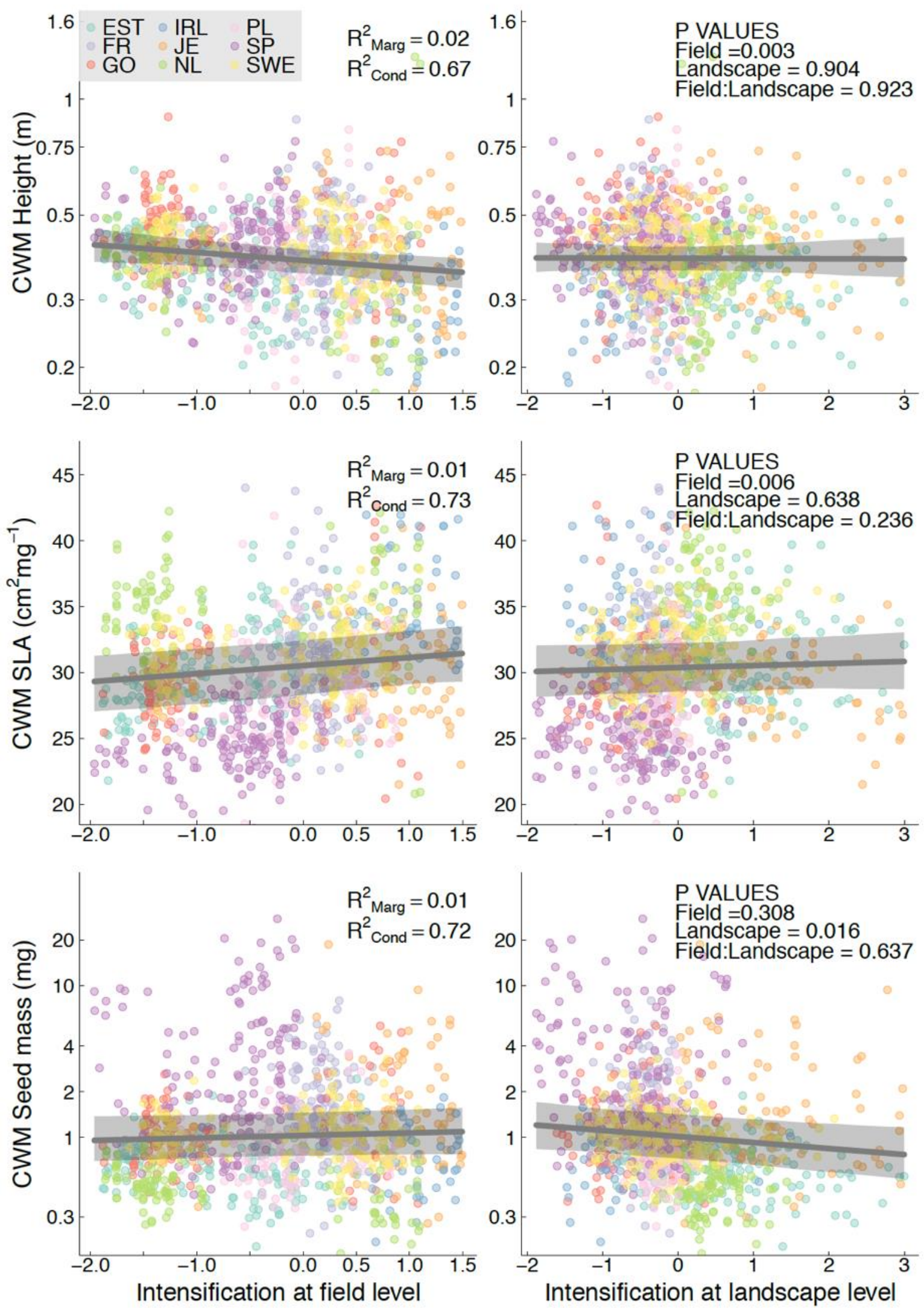

750 Fig. 3. 

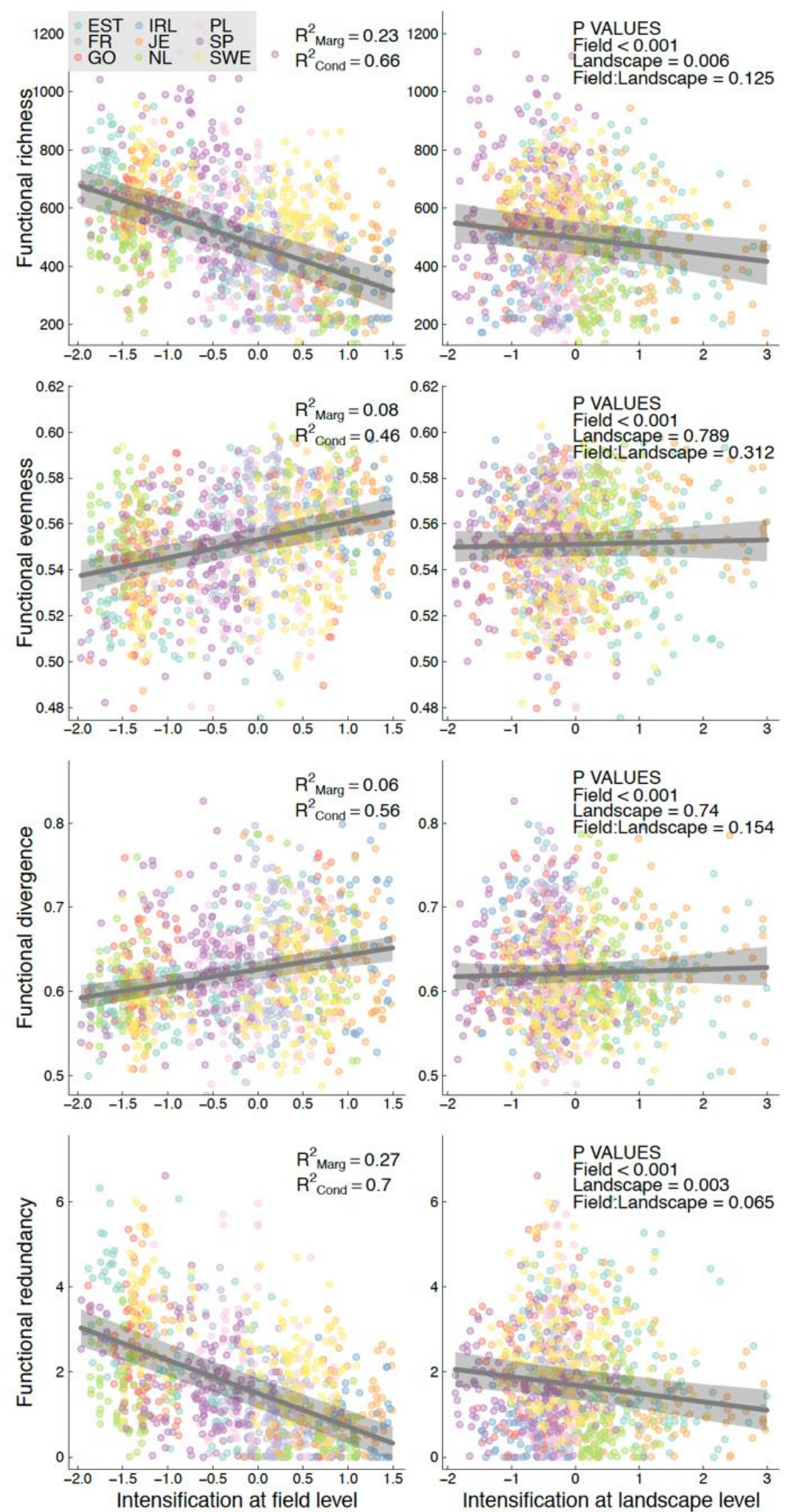

752 Fig. 4. 
754 Appendix S1. References for individual datasets included in the TRY database from which trait information was used.

756 Table S1. Mean and standard deviation of agricultural intensification values at the field and landscape levels for each study area.

758 Table S2. Comparisons of models considering and not considering random slopes for the study areas.

760 Fig. S1. Biplot of the principal components analysis (PCA).

761 Fig. S2. Partial regression plots showing the effects of agricultural intensification at the field and landscape levels on functional richness SES.

763 Fig. S3. Partial regression plots showing the effects of agricultural intensification at the field and landscape levels on relative functional redundancy (functional redundancy after removing the effect of species richness). 